and after the slabs have solidified samples are cut and ground and the activity measured.

A technique in which ${ }^{198} \mathrm{Au}$ is used to trace sediment movement in the sea has recently been adopted in South Africa in the study of harbour development. The gold tracer is attached to a sand sample by chemical exchange with silver previously deposited on to the sample by a chemical silvering process.

At the test site the radioactive sand is mixed with a sediment slurry in a lead shielded pot, which is lowered to the sea bed and emptied by remote control from the deck. The labelled sand particles are transported by the sea movements and their dispersal can then be traced by means of a sensitive gamma detector towed across the sea bed. This technique has two important advantages over a fluorescent tracer technique previously employed; the tracer material can be readily identified and the dispersion of sediment can be observed directly and correlated with data on winds and tide movements.

In the laboratory the $67 \mathrm{KeV} \mathrm{K} \mathrm{X-ray} \mathrm{from} \mathrm{a} \mathrm{source}$ of ${ }^{195} \mathrm{Au}$ has been used in X-ray fluorescence spectrometry, but this application is restricted by the high cost and comparatively short half-life of the nuclide.

The transitions of ${ }^{195} \mathrm{Au}$ which generate 98.8 and $129 \mathrm{KeV}$ gamma rays exhibit the Mössbauer effect This has been used in studies of the physical and chemical structure of metallic platinum and its alloys, of intermetallic compounds and of oxides and halides.

\title{
Gold Alloy Spark Plug Electrodes
}

\section{EASIER STARTING AND LONGER LIFE}

To perform its function efficiently a spark plug must maintain a gap spacing that will satisfy engine operation over the full range of output from idling to full throttle, achieve this with minimum fuel consumption, and resist the effects of both electrical erosion and chemical attack from the products of combustion.

A very great deal of research has gone into the design and development of the spark plug to meet modern conditions of motoring. One recent development, by Champion Spark Plug of Toledo, Ohio, is the introduction of a range of plugs with centre electrodes tipped with gold alloy wire. These spark plugs, although somewhat more expensive, have been enthusiastically adopted in such applications as snowmobiles and motorcycles where fast and sure starting is required even in sub-zero weather conditions.

The use of the gold alloy electrode - a 60 per cent gold 40 per cent palladium alloy - offers a number of advantages in engine performance, including easier starting and less gap erosion. Easier starting results from reduced voltage required to fire the plug. In addition, since the small size of the electrode means that more spark is exposed to the fuel charge than with standard electrodes, the gap size can be reduced, which again lowers the voltage demand on the ignition system.

The outstanding resistance to corrosion of the goldpalladium alloy has made it possible to design these

The centre electrode of this Champion spark plug in a goldpalladium alloy is specifically designed to provide ease of starting even in extremely cold weather conditions, while the high resistance to corrosion of the gold alloy ensures a longer service life than can be expected with plugs fitted with conventional electrodes

plugs with a smaller diameter insulator tip, allowing greater clearance between the insulator and the shell at the firing end. This results in better scavenging of fuel deposits and, as a consequence, better protection from fouling. Similarly the marked decrease in gap erosion observed with these plugs is attributable to the much greater resistance of the gold alloy to the atmosphere in the combustion chamber by comparison with the more conventional electrode materials.

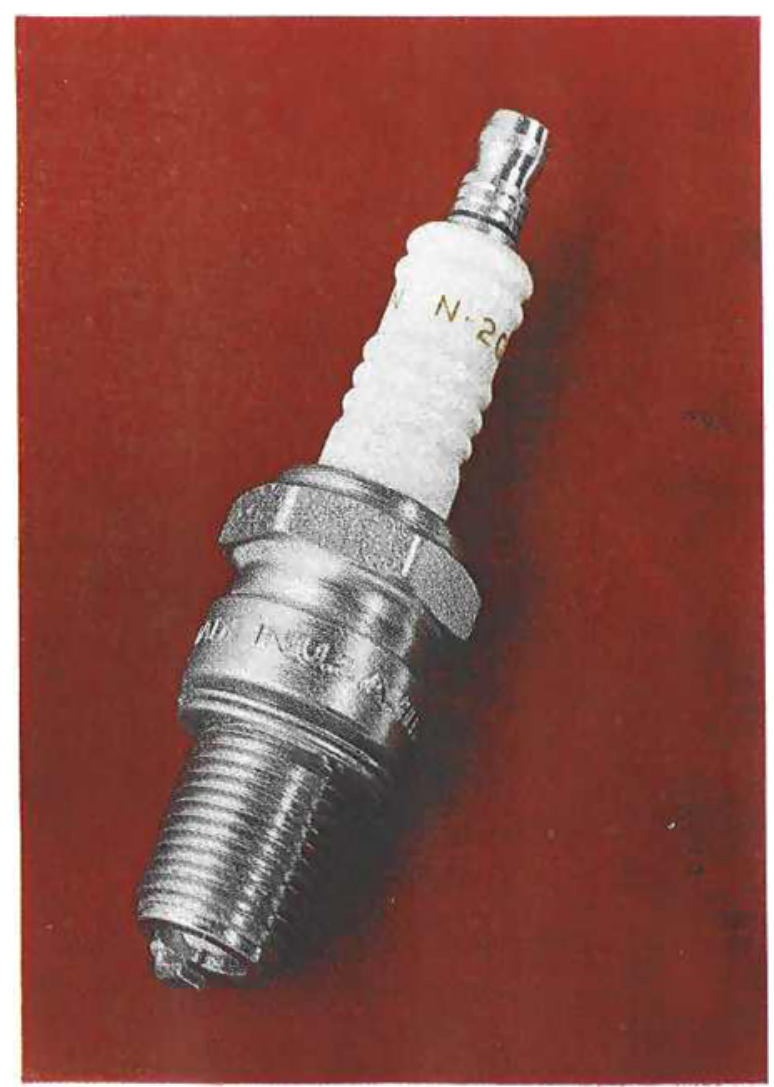

